\title{
PERDAS DE SOLO E ÁGUA POR EROSÃO HÍDRICA APÓS MUDANÇA NO TIPO DE USO DA TERRA, EM DOIS MÉTODOS DE PREPARO DO SOLO E DOIS TIPOS DE ADUBAÇÃO(1)
}

\author{
Tatiane Bagatini ${ }^{(2)}$, Neroli Pedro Cogo ${ }^{(3)}$, Luciléia Gilles ${ }^{(4)}$, Jeane Cruz

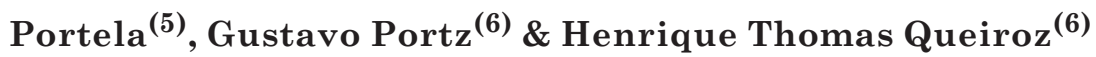

\begin{abstract}
RESUMO
A mudança no tipo de uso da terra, se não devidamente planejada e conduzida, poderá resultar em solos com capacidade produtiva diminuída e com propensão à erosão aumentada, o que irá diminuir o rendimento das culturas e prejudicar a conservação do solo e da água. Esta pesquisa teve como objetivo avaliar a erosão hídrica pluvial do solo em área originalmente de campo nativo, nos seus segundo e terceiro anos de cultivo com culturas anuais em fileira (respectivamente, feijãomiúdo - Vigna unguiculata - e sorgo - Sorghum bicolor), nos métodos de preparo do solo reduzido (escarificação) e sem preparo (semeadura direta) e nos tipos de adubação mineral (fertilizante NPK) e orgânica (cama de aviário), além de uma condição sem adubação (tratamento testemunha). O estudo foi desenvolvido em campo, na EEA/UFRGS, em Eldorado do Sul (RS), nos verões de 2007/2008 e 2008/ 2009. Usou-se chuva simulada e um Argissolo Vermelho distrófico típico com textura franco-arenosa na camada superficial e declividade média de $0,13 \mathrm{~m} \mathrm{~m}^{-1}$. Realizaram-se dois testes de erosão em cada ciclo cultural: o primeiro, logo após o preparo do solo e a semeadura das culturas; e o segundo, cerca de 90 dias mais tarde (estádio fenológico de enchimento de legumes, no caso do feijão-miúdo, e de maturação, no do sorgo). As chuvas foram aplicadas com o simulador de braços rotativos, na intensidade planejada de $64 \mathrm{~mm} \mathrm{~h}^{-1}$ e com duração de 1,5 h cada uma.
\end{abstract}

\footnotetext{
(1) Parte da Dissertação de Mestrado do primeiro autor apresentada ao Programa de Pós-Graduação em Ciência do Solo da Universidade Federal do Rio Grande do Sul - UFRGS; realizada com recursos financeiros do Auxílio "grant" do CNPq. Recebido para publicação em abril de 2010 e aprovado em janeiro de 2011.

(2) Mestranda em Ciência do Solo, Universidade Federal do Rio Grande do Sul - UFRGS. Av. Bento Gonçalves 7712, CEP 915400000 Porto Alegre, (RS). Bolsista de pós-graduação do CNPq. E-mail: tatibagatini@yahoo.com.br

(3) Professor Associado III, Departamento de Solos, Faculdade de Agronomia, UFRGS. Bolsista do CNPq. E-mail: neroli@ufrgs.br.

(4) Mestra em Ciência do Solo, UFRGS. Ex-bolsista da CAPES. E-mail: leiagilles@yahoo.com.br

(5) Doutora em Ciência do Solo, UFRGS. Ex-bolsista CNPq. E-mail: jeanecportela@yahoo.com.br

${ }^{(6)}$ Acadêmicos da Faculdade de Agronomia, UFRGS. Bolsistas de iniciação científica da FAPERGS. E-mail: gportz@gmail.com; henrique.agro@yahoo.com.br
} 
Os resultados evidenciaram que a mudança no tipo de uso da terra, excluída a condição sem adubação, não ocasionou perdas relevantes de solo e água por erosão hídrica. A mobilização do solo pela escarificação, na maior parte dos casos, favoreceu a infiltração e a retenção superficial da água da chuva e, em decorrência, reduziu a enxurrada, ao mesmo tempo em que satisfatoriamente controlou a erosão. Por sua vez, a ausência de mobilização do solo na semeadura direta, também na maior parte dos casos, induziu a formação de maior enxurrada, porém controlou melhor a erosão. Comparadas à condição sem adubação, a adubação mineral e a adubação orgânica contribuíram para reduzir a enxurrada e a erosão nos dois métodos de preparo do solo investigados, sem diferenças definidas entre elas em qualquer um destes últimos.

Termos de indexação: chuva simulada, cobertura do solo, rugosidade superficial do solo.

\section{SUMMARY: SOIL AND WATER LOSSES BY EROSION AFTER LAND USE CHANGE, IN RELATION TO TWO TILLAGE METHODS AND TWO FERTILIZATION TYPES}

A change in the type of land use, if not properly planned and conducted, may result in soils with diminished production capacity and increased erosion susceptibility, which will reduce crop yields and hamper soil and water conservation. This study had the purpose of investigating the soil erosion caused by rainfall in an originally native pasture area, in the second and third year of cultivation of two annual row crops (respectively, cowpea - Vigna unguiculata - and shorgum - Shorgum bicolor), under reduced tillage (chiseling) and without mobilization (no tillage) and two fertilization types, mineral (NPK fertilizer) and organic (poultry bed), besides a treatment without fertilization (control). The study was developed in the field, at the Agriculture Experimental Station of the Federal University of Rio Grande do Sul (EEAUFRGS), in Rio Grande do Sul State, Brazil, in the summer growing seasons of 2007/2008 and 2008/2009. An Ultisol with a sandy loam texture in the surface layer and $0.13 \mathrm{~m} \mathrm{~m}$ ${ }^{1}$ average slope steepness under simulated rainfall were used in the study. Two erosion tests were performed in each crop cycle, the first immediately after soil tillage and crop seeding and the second about 90 days later (pod filling stage of cowpea and maturation of sorghum). Rains with $64 \mathrm{~mm} \mathrm{~h}^{-1}$ rainfall intensity and $1.5 \mathrm{~h}$ duration were applied by a rotating-boom rainfall simulator. The results evidenced, excluding the treatment without fertilization, that the land use change caused no relevant soil and water losses by rainfall erosion. Soil mobilization by chiseling, in most cases, favored surface infiltration and surface retention of rainfall water in the soil and, as consequence, reduced the surface runoff, while also controlling erosion satisfactorily. On the other hand, the absence of soil mobilization in no tillage, also in the majority of cases, induced greater surface runoff, but controlled erosion better. Compared to the treatment without fertilizer, mineral and organic fertilization both helped to reduce runoff and erosion, without definite differences in both tillage methods.

Index terms: simulated rainfall, soil cover, soil surface roughness.

\section{INTRODUÇÃO}

A causa fundamental da erosão hídrica nas terras cultivadas é a ação da chuva diretamente no solo. Assim, a quantidade final de erosão em um dado local irá depender da combinação do poder da chuva de causar erosão no solo (erosividade) e da capacidade do solo de resistir à ação da chuva (erodibilidade). Vários fatores interferem nesse processo, destacando-se o regime de chuva, o tipo de solo, o comprimento e a inclinação do declive, a cobertura e o manejo do solo e as práticas conservacionistas de suporte (Wischmeier \& Smith 1978; Hudson, 1995). Uma vez que a erosão é um processo predominantemente de superfície, as condições físicas da camada superficial do solo, externas e internas, em última análise são as que irão determinar as perdas totais finais de solo e água pelo fenômeno em determinado local. Basicamente, essas condições irão depender do tipo de uso da terra e da forma como o solo e a cultura são manejados, os quais irão induzir diferentes graus de cobertura, rugosidade e consolidação superficiais, bem como 
diferentes características e propriedades físicas internas do solo, especialmente volume total e distribuição de tamanho de poros e estabilidade e distribuição de tamanho de agregados, além do conteúdo de matéria orgânica. No conjunto, essas condições serão as determinantes tanto da resistência do solo à ação erosiva da água da chuva e da enxurrada a ela associada, quanto da facilidade com que a primeira irá infiltrar no solo e se movimentar no seu interior, resultando em maior ou menor perda de solo e água por erosão hídrica (Wischmeier, 1973; Wischmeier \& Smith, 1978; Renard et al., 1997).

A substituição da vegetação nativa por plantas cultivadas, principalmente as de ciclo anual e dispostas em fileiras, normalmente causa desequilíbrio no ecossistema. Isso ocorre porque a mudança no tipo de uso da terra, e decorrentes novas formas de manejar o solo e as culturas, irão modificar as condições químicas, físicas e biológicas do solo, restringindo suas funções primárias e, com isso, podendo levá-lo à degradação (Schröder et al., 2002). O efeito do uso anterior da terra na erosão hídrica irá variar conforme o uso e o manejo específico ao qual o solo será submetido. Streck \& Cogo (2003) observaram que, quando a substituição do uso da terra de campo nativo para área com culturas anuais em fileira foi feita usando o método convencional de preparo ou uma aração e duas gradagens, o efeito residual do uso da terra nas perdas de solo e água por erosão hídrica persistiu, embora diminuindo progressivamente por dois anos, após o que deixou de existir e, então, tanto a erosão quanto a enxurrada nivelaram. Esses aspectos são comentados de modo detalhado em Wischmeier \& Smith (1978). Já com culturas anuais em fileira seguindo culturas anuais em fileira, implantadas em semeadura direta por três anos e, então, voltando-se a preparar o solo com uma aração e duas gradagens, o efeito do uso anterior da terra na erosão hídrica foi bem menor (cerca de seis meses), conforme estudo realizado por Volk \& Cogo (2008).

Os métodos de preparo do solo também têm grande influência na erosão hídrica pluvial, no que se refere tanto à perda de água quanto à perda de solo, porém diferenciando-se entre si por resultarem em diferentes condições físicas externas e internas do solo, mas principalmente as primeiras, alterando a erosão e a enxurrada de modo diferente. Assim, entre os preparos conservacionistas, o denominado de reduzido, o qual no Brasil tem a escarificação (seguida ou não de gradagem) como o seu representante mais comum, caracteriza-se por apresentar de média a grande rugosidade e pouca ou nenhuma consolidação superficial, decorrendo disso maior porosidade total na camada mobilizada do solo, porém menor cobertura por resíduos culturais, quando comparado ao método sem preparo do solo ou técnica de semeadura direta. Isso ocorre porque os métodos de preparo do solo variam em extensão de superfície do terreno trabalhada, profundidade de preparo e grau de fragmentação da massa de solo mobilizada (tamanho dos torrões), dessa forma influenciando tanto as taxas de perda quanto as perdas totais de água e solo por erosão hídrica também de modo variado (Cogo et al., 1983; Volk et al., 2004, 2008; Gilles et al., 2009; Portela et al, 2010).

A cobertura por resíduos culturais e a rugosidade superficial induzida pelos métodos de preparo são as condições físicas de superfície do solo mais importantes no que diz respeito ao controle da erosão hídrica pluvial e do escoamento superficial a ela associado. A permanência dos resíduos culturais na superfície do solo é de fundamental importância porque eles atuam na dissipação (parcial ou total, dependendo do grau de cobertura) da energia cinética das gotas da chuva rente à superfície do solo, não permitindo dessa forma reaquisição de energia no processo e, em consequência, evitando ou minimizando a desagregação inicial de suas partículas e a formação de selos e, ou, crostas superficiais, resultando em aumento da infiltração da água da chuva e em diminuição da enxurrada. Além desses benefícios, a cobertura superficial do solo, seja ela constituída por resíduos culturais ou plantas vivas (rasteiras), irá atuar como excelente barreira física na diminuição da velocidade da enxurrada e, concomitantemente a isso, irá filtrar e induzir a deposição das partículas desagregadas do solo que se encontram sob processo de transporte no próprio local de ocorrência do fenômeno (Cogo, 1981; Cogo et al., 1984, 2003). Por sua vez, a rugosidade superficial do solo induzida pelos métodos de seu preparo é importante porque ela aumenta a capacidade de infiltração e retenção da água da chuva na sua superfície e, em adição, aprisiona os sedimentos da erosão no microrrelevo formado, reduzindo o volume e a velocidade da enxurrada. Os fatos mencionados, em conjunto, irão determinar pequena, média ou grande perda de solo e água por erosão hídrica pluvial, dependendo da presença e do nível das variáveis envolvidas (Cogo, 1981; Cogo et al., 1983; Castro et al., 2006; Volk \& Cogo, 2009). Com base nas considerações efetuadas, pode-se dizer que, na escarificação, seguida ou não de gradagem, devido à sua média a alta rugosidade superficial e manutenção de, ainda, boa cobertura por resíduos culturais ( 30 a $60 \%$ ), os valores de perda de solo e água por erosão hídrica irão ser substancialmente reduzidos (Cogo et al., 1983; Gilles et al., 2009). Já o método sem preparo do solo ou técnica de semeadura direta, por causa da sua pequena ou mínima rugosidade superficial, em função da sua mínima mobilização de solo, em geral irá apresentar maiores valores de perda de água na forma de enxurrada do que a escarificação (Gilles et al., 2009). Contudo, devido ao relativamente alto grau de consolidação superficial e manutenção da quase totalidade dos resíduos culturais na superfície do solo na referida técnica, os seus valores de perda de solo normalmente são menores do que na escarificação, em que pese o fato de esta última também ser bastante eficaz na redução da erosão (Cogo et al., 1983, 1984; Castro et al., 2006; Gilles et al., 2009). 
Quanto ao efeito do tipo de adubação nas condições físicas do solo, as poucas pesquisas realizadas sobre o assunto têm demonstrado que a utilização de adubação orgânica, independentemente do seu tipo, em geral melhora suas características e propriedades físicas internas, quando comparada à adubação mineral, conforme estudos realizados por Diana et al. (2007), Pires et al. (2008) e Zhao et al. (2009). Esses autores observaram que, sob adubação orgânica, houve aumento da taxa de infiltração de água no solo, diminuição da densidade global e aumento da porosidade total e do tamanho médio dos agregados, entre outros efeitos positivos, de mesma ou de diferente natureza. Isso é explicado pelo aumento do teor de matéria orgânica no solo, em função do contínuo aporte de material orgânico a este. Quanto ao efeito do tipo de adubação, química ou orgânica, na erosão hídrica pluvial, as pesquisas são ainda mais escassas, sobretudo no nosso meio. Um trabalho realizado por Gilles et al. (2009) evidenciou que a variação nos resultados de perda de solo e água por erosão hídrica (chuva simulada), relacionados com adubação mineral e com adubação orgânica, foi bastante expressiva, ora um, ora outro tipo delas tendo se mostrado o melhor.

Com base no exposto, evidencia-se a necessidade de desenvolver mais pesquisas sobre o assunto. Assim, este trabalho foi realizado com o objetivo de avaliar as alterações nas condições físicas do solo, causadas por diferentes formas de seu manejo, após mudança no tipo de uso da terra, e posteriormente relacioná-las com a erosão hídrica pluvial e com a enxurrada a ela associada.

\section{MATERIAL E MÉTODOS}

O estudo foi desenvolvido em campo, na Estação Experimental Agronômica da Universidade Federal do Rio Grande do Sul (EEA/UFRGS), município de Eldorado do Sul (RS), nos verões de 2007/2008 e 2008/ 2009, sobre um Argissolo Vermelho distrófico típico (Streck et al., 2008), possuindo textura franco-arenosa na camada superficial e declividade média de $0,13 \mathrm{~m} \mathrm{~m}^{-1}$.

Originalmente a área experimental era campo nativo. No início desta pesquisa, entretanto, a referida área se encontrava na condição de pousio de inverno, após ter passado por cultivo anual (o primeiro, com milho - Zea mays, no verão de 2006/2007), em função de um estudo desenvolvido por Gilles et al. (2009). As culturas usadas no presente estudo foram as de feijãomiúdo (Vigna unguiculata), no verão de 2007/2008, e de sorgo (Sorghum bicolor), no verão de 2008/2009. Antes da semeadura do feijão-miúdo, efetuou-se a dessecação das plantas espontâneas vigentes na área, por meio da aplicação de herbicida (glifosate). Após a colheita do feijão-miúdo, efetuou-se a semeadura da aveia-preta (Avena strigosa), a qual, após ter completado seu ciclo, também foi dessecada quimicamente, tendo então sido semeado o sorgo.

Os tratamentos estudados constituíram-se de métodos de preparo do solo e tipos de adubação, a saber: (a) escarificação, sem adubação - ESC, sem ad. testemunha 1; (b) escarificação, adubação mineralESC, ad. min.; (c) escarificação, adubação orgânica ESC, ad. org.; (d) semeadura direta, sem adubação $\mathrm{SD}$, sem ad. - testemunha 2; (e) semeadura direta, adubação mineral - SD, ad. min., e (f) semeadura direta, adubação orgânica - SD, ad. org. Sempre que necessário, efetuou-se irrigação (aspersão) nas parcelas experimentais de todos os tratamentos arrolados.

A operação de escarificação, nos dois anos de experimentação, foi realizada com escarificador de hastes parabólicas, com cinco ponteiras estreitas $(0,06 \mathrm{~m}$ cada uma), espaçadas de $0,45 \mathrm{~m}$, as quais operaram no solo à profundidade de $0,20-0,25 \mathrm{~m}$. Esse equipamento portava rolo destorroador em sua parte traseira. A semeadura do feijão-miúdo foi realizada com máquina de semeadura direta do tipo com discos (duplos) desencontrados, seguidos de hastes sulcadoras $(0,02 \mathrm{~m}$ de largura), as quais operaram no solo à profundidade de 0,06-0,08 m. Essas hastes sulcadoras são usadas com a finalidade de colocar o adubo em profundidade no solo $(0,06 \mathrm{~m}$ a $0,12 \mathrm{~m})$. Neste estudo, entretanto, uma vez que os adubos, nos dois métodos de preparo do solo investigados, foram aplicados manual e superficialmente, a lanço, antes do preparo do solo e da semeadura das culturas, as referidas hastes sulcadoras serviram apenas para causar certa mobilização do solo nos tratamentos com semeadura direta. A semeadura do sorgo foi realizada com máquina de semeadura direta do tipo com fluxo contínuo, com as sementes tendo sido colocadas no solo à profundidade de $0,02-0,03 \mathrm{~m}$. As operações de preparo do solo e semeadura das culturas foram sempre realizadas no sentido do declive, conforme filosofia de obtenção de valores do Fator $\mathrm{C}$ - cobertura e manejo do solo dos modelos "USLE - Universal Soil Loss Equation" e "RUSLE - Revised Universal Soil Loss Equation" de predição da erosão hídrica (respectivamente, Wischmeier \& Smith, 1978; e Renard et al., 1997). O espaçamento usado na semeadura do feijão-miúdo foi de $0,45 \mathrm{~m}$ entre fileiras, correspondendo à população aproximada de 350.000 plantas $\mathrm{a}^{-1}$, enquanto na do sorgo foi de $0,17 \mathrm{~m}$, tendo sido usados $15 \mathrm{~kg}$ de sementes ha ${ }^{-1}$. A quantidade de adubos (superfosfato triplo, cloreto de potássio e ureia) nos tratamentos com adubação mineral foi baseada no Manual de Adubação e de Calagem para os Estados do RS e SC (CQFSRS/SC, 2004), para cada uma das culturas. A adubação orgânica foi constituída de cama seca de aviário, em quantidade baseada no seu conteúdo total de P.

Antes do preparo do solo e da semeadura das culturas, o solo da área experimental foi caracterizado em termos de teor de matéria orgânica e valores de 
alguns de seus atributos físicos. Assim, para determinação do diâmetro médio ponderado (DMP) de agregados, foram coletadas amostras compostas de solo em cada parcela experimental, cada uma delas constituídas de duas subamostras, retiradas da camada de solo de $0-0,10 \mathrm{~m}$. Para as determinações de densidade, macroporosidade, microporosidade e porosidade total do solo, coletaram-se aleatoriamente duas amostras em cada parcela experimental, da camada de solo também de $0-0,10 \mathrm{~m}$. O DMP de agregados do solo foi determinado usando-se amostras constituídas de partículas com diâmetro entre 7,93 e $4,76 \mathrm{~mm}$, por meio da técnica de peneiramento em água (Kemper \& Chepil, 1965). A densidade, a macro, a micro e a porosidade total do solo foram determinadas usando amostras com estrutura não deformada, coletadas em cilindros metálicos com $0,085 \mathrm{~m}$ de diâmetro e $0,05 \mathrm{~m}$ de altura, sendo analisadas conforme descrito em Embrapa (1997). Antes da aplicação das chuvas simuladas, amostrouse o solo nas camadas de $0-0,10 \mathrm{~m}$ e $0,10-0,20 \mathrm{~m}$, para determinação da umidade gravimétrica (Forsythe, 1975), bem como a percentagem de cobertura por resíduos culturais, pelo método da linha de transeção de pontos (Hartwig \& Laflen, 1978).

O aparelho simulador de chuva utilizado no estudo foi o de braços rotativos (Swanson, 1965), com as chuvas tendo sido aplicadas na intensidade planejada de $64,0 \mathrm{~mm} \mathrm{~h}^{-1}$ e com duração de $1,5 \mathrm{~h}$ cada uma, simultaneamente sobre duas unidades experimentais com 3,5 m de largura por 11,0 m de comprimento cada uma. Foram realizados dois testes de erosão em cada ciclo cultural: o primeiro, logo após o preparo do solo e a semeadura das culturas (dezembro de 2007, no caso do feijão-miúdo, e dezembro de 2008, no do sorgo); e o segundo, cerca de 90 dias mais tarde (estádio fenológico de enchimento de legumes, no caso do feijão-miúdo março de 2008; e de maturação, no do sorgo - março de 2009). Uma semana antes da realização do segundo teste de erosão, nos dois anos de experimentação, foi feita nova amostragem do solo nas parcelas experimentais, na sua camada de $0-0,10 \mathrm{~m}$, tendo sido determinados o DMP de agregados, a densidade, a macro, a micro e a porosidade total, usando-se o mesmo método descrito anteriormente. Nessa mesma época, foram também medidos alguns atributos de planta, como a altura média, a biomassa aérea e a biomassa de raízes. A altura média de plantas foi medida com fita métrica, tomando-se 20 plantas representativas em cada parcela experimental. A determinação da biomassa aérea foi feita por meio da coleta de plantas de uma área de $1 \mathrm{~m}^{2}$, em cada parcela experimental. A determinação da biomassa subterrânea (raízes) foi feita coletando-se uma amostra composta de solo, constituída de seis subamostras, em cada parcela experimental, na camada de solo de $0-0,10 \mathrm{~m}$, usando trado cilíndrico com $0,059 \mathrm{~m}$ de diâmetro, nas regiões da fileira e entre fileiras das plantas, em cada parcela experimental. As amostras para determinação da biomassa de raízes foram levadas ao laboratório, postas a secar ao ar (três a quatro dias), destorroadas manualmente e lavadas sob jato de água de torneira, sobre peneira com abertura de malha de $0,5 \mathrm{~mm}$, para separar as raízes da massa de solo que as continham; posteriormente, foram secas em estufa a $60{ }^{\circ} \mathrm{C}$, por 24 horas.

No que se refere às variáveis de erosão hídrica, mediu-se o tempo de início da enxurrada, com cronômetro, a partir do início das chuvas simuladas; a lâmina de água da chuva infiltrada e retida na superfície do solo no período de pré-enxurrada, por cálculo direto (regra de três simples), tomando-se o tempo de início da enxurrada e a intensidade das chuvas aplicadas; a perda total de água, integrandose no tempo os valores observados das taxas de descarga da enxurrada, medidas no campo, com proveta graduada e cronômetro, a cada três minutos; e a perda total de solo, por integração dos valores resultantes da multiplicação dos dados observados de taxas de descarga da enxurrada pelos das suas correspondentes concentrações de sedimento, medidas também a cada três minutos, em amostras de enxurrada coletadas em potes plásticos com capacidade de armazenamento de $1 \mathrm{~L}$ cada um, empregando-se alúmen de potássio comercial a $5 \%$ para precipitar os sedimentos nelas contidos, conforme descrito em Cogo (1981).

\section{RESULTADOS E DISCUSSÃO}

\section{Variáveis de manejo do solo}

No quadro 1 são apresentados os resultados da avaliação do teor de matéria orgânica e de alguns atributos físicos do solo usado na pesquisa, na sua condição original de campo nativo, efetuada por Gilles et al. (2009), em cada local onde, poucos dias mais tarde, foram implantados os tratamentos do seu estudo (verão de 2006/2007), tendo o milho como planta-teste. Esses tratamentos foram os mesmos deste estudo, porém tendo o feijão-miúdo e o sorgo como plantas-teste no segundo e terceiro cultivos, respectivamente, de ciclo anual na área experimental. Analisando os dados, observa-se que, tendo em vista a variabilidade natural do solo, os resultados obtidos podem ser considerados próximos uns dos outros, denotando sua satisfatória homogeneidade na área experimental, para os fins desta pesquisa. Dos valores apresentados no quadro 1, cabe destacar os de densidade do solo (Ds), relativamente altos, e os de macroporosidade e porosidade total, relativamente baixos, do ponto de vista de desenvolvimento do sistema radicular das plantas e de infiltração de água no solo, em que pese o fato de o diâmetro médio ponderado (DMP) de agregados estar com valores altos. Essas ocorrências podem ser explicadas pelo tipo de solo usado na pesquisa (Argissolo Vermelho) e pelo tipo de uso da terra até então vigente (pastagem nativa). 
Quadro 1. Teor de matéria orgânica e valores de alguns atributos físicos do solo usado na pesquisa (camada de 0 - 0,10 m), na sua condição original de campo nativo, avaliados no verão de 2006/2007 por Gilles et al. (2009), em cada local onde foram instalados os tratamentos de seu estudo

\begin{tabular}{|c|c|c|c|c|c|c|c|c|c|c|}
\hline \multirow{2}{*}{ Tratamento } & \multicolumn{3}{|c|}{ Granulometria } & \multirow{2}{*}{$\mathrm{D} \mathbf{p}^{(1)}$} & \multirow{2}{*}{ MO $^{(2)}$} & \multirow{2}{*}{$\operatorname{DMP}^{(3)}$} & \multirow{2}{*}{$D s^{(4)}$} & \multicolumn{3}{|c|}{ Porosidade do solo } \\
\hline & Areia & Silte & Argila & & & & & Macro & Micro & Total \\
\hline & & $\mathrm{g} \mathrm{kg}^{-1}$ & & $\mathrm{Mg} \mathrm{m}^{-3}$ & $\mathrm{~g} \mathrm{~kg}^{-1}$ & $\mathrm{~mm}$ & $\mathrm{Mg} \mathrm{m}^{-3}$ & 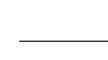 & $\mathrm{m}^{3} \mathrm{~m}^{-3}$ & \\
\hline $\mathrm{P} 1 / \mathrm{ESC}^{(5)}$, sem adubação & 518,5 & 343,0 & 139,0 & 2,49 & 33,0 & 4,75 & 1,47 & 0,11 & 0,34 & 0,45 \\
\hline P2/ESC, adubação mineral & 555,5 & 304,0 & 141,0 & 2,51 & 29,5 & 5,10 & 1,51 & 0,08 & 0,33 & 0,41 \\
\hline P3/ESC, adubação orgânica & 571,0 & 287,0 & 142,5 & 2,60 & 28,0 & 4,30 & 1,48 & 0,11 & 0,31 & 0,42 \\
\hline $\mathrm{P} 4 / \mathrm{SD}^{(6)}$, sem adubação & 521,0 & 318,5 & 161,5 & 2,42 & 29,0 & 5,15 & 1,53 & 0,06 & 0,37 & 0,43 \\
\hline P5/SD, adubação mineral & 532,0 & 324,5 & 143,5 & 2,53 & 29,5 & 4,85 & 1,59 & 0,07 & 0,31 & 0,38 \\
\hline P6/SD, adubação orgânica & 582,0 & 291,0 & 127,5 & 2,52 & 25,5 & 5,15 & 1,51 & 0,14 & 0,28 & 0,42 \\
\hline
\end{tabular}

(1) Densidade de partículas. ${ }^{(2)}$ Matéria orgânica. ${ }^{(3)}$ Diâmetro médio ponderado de agregados. ${ }^{(4)}$ Densidade do solo. ${ }^{(5)}$ Escarificação.

(6) Semeadura direta.

No quadro 2 são apresentados os resultados da avaliação do teor de matéria orgânica e de alguns atributos físicos do solo, na sua camada de $0-0,10 \mathrm{~m}$, efetuada em três épocas durante a condução dos experimentos deste estudo, antecedendo a realização de três testes de erosão neles efetuados, após conversão do uso da terra de pastagem nativa para área com culturas anuais em fileira (segundo e terceiro anos de experimentação). Por questões operacionais, não foi possível medir os atributos em consideração na época correspondendo à semeadura do feijão-miúdo.

Analisando os dados no quadro 2, verifica-se certa irregularidade neles, tanto entre os tratamentos em uma mesma época de avaliação quanto entre estas últimas em um mesmo tratamento; assim, sem tendência clara de comportamento quanto ao efeito tanto dos métodos de preparo do solo quanto dos tipos de adubação, mas, de modo geral, tendo se situado numa faixa relativamente estreita de variação. Esse acontecimento, em parte, pode ser explicado pelo pouco tempo de experimentação (três anos) e pelo relativamente pequeno número de amostras coletadas nas parcelas experimentais, para efetuar essas determinações. Observa-se no quadro 2 certa tendência de os teores de matéria orgânica (MO) e valores de macroporosidade serem maiores, e os de densidade do solo, menores, na avaliação efetuada por ocasião da semeadura do sorgo. Uma explicação para isso pode estar associada à grande quantidade de raízes da cultura de inverno (aveia-preta), presente no solo nessa época de avaliação. Os demais atributos físicos avaliados (diâmetro médio ponderado de agregados, microporosidade e porosidade total - Quadro 2) praticamente não se diferenciaram nas diferentes situações da pesquisa. Resultados como esses foram também observados por Oliveira et al. (2003), Bertol et al. (2004) e Debiasi et al. (2008), em estudos de natureza semelhante à deste.

No quadro 3 são apresentados os resultados da avaliação da cobertura do solo pelos resíduos culturais dos cultivos anteriores, bem como da rugosidade superficial induzida pelo preparo e da consolidação da camada arável - estas duas últimas obtidas por meio da observação visual, efetuadas logo após as operações de preparo do solo e semeadura das culturas. Analisando os dados no referido quadro, verifica-se que a cobertura do solo por resíduos culturais e a consolidação da camada arável do solo foram maiores nos tratamentos com semeadura direta, ao passo que a rugosidade superficial induzida pelo preparo foi maior nos tratamentos com escarificação, devido, respectivamente, à não mobilização e à mobilização do solo. O relativamente baixo valor de cobertura do solo por resíduos culturais logo após a semeadura do feijão-miúdo se deveu ao fato de não ter sido efetuado o cultivo de inverno em 2007; por conseguinte, não tendo sido produzida a quantidade de resíduos culturais que se produziria caso ele tivesse sido realizado. Já no verão de 2008/2009, tendo em vista ter sido feita a semeadura da cultura de inverno em 2008 (aveia-preta), a quantidade de resíduos culturais produzida foi grande, principalmente nos tratamentos com adubação, cujo valor médio se situou em torno de $7.000 \mathrm{~kg} \mathrm{ha}^{-1}$, contra o valor médio de $2.500 \mathrm{~kg} \mathrm{ha}^{-1}$ nos tratamentos sem adubação. Em razão disso, os valores de cobertura do solo por resíduos culturais, no último verão da pesquisa, foram maiores do que no verão anterior, principalmente nos tratamentos com semeadura direta. Quanto à rugosidade superficial do solo induzida pelo preparo, avaliada em termos qualitativos, verifica-se no quadro 3 que resultou de média a grande na escarificação e de mínima a pequena na semeadura direta. Como será visto adiante, a rugosidade superficial do solo induzida pelo preparo influenciou os atributos de erosão hídrica avaliados neste estudo. No que se refere à consolidação da camada arável do solo (Quadro 3), em grande extensão de superfície, esteve presente somente nos tratamentos com semeadura direta, uma vez que, nos com escarificação, o solo foi substancialmente 
Quadro 2. Teor de matéria orgânica e valores de alguns atributos físicos do solo (camada de 0 - 0,10 m), avaliados em três épocas durante a condução dos experimentos deste estudo (uma no verão de 2007/ 2008 e duas no verão de 2008/2009), antecedendo os testes de erosão nelas realizados, nos tratamentos estudados

\begin{tabular}{|c|c|c|c|c|c|c|}
\hline \multirow{2}{*}{ Tratamento } & \multirow{2}{*}{$\mathrm{MO}^{(1)}$} & \multirow{2}{*}{$\operatorname{DMP}^{(2)}$} & \multirow{2}{*}{ Densidade do solo } & \multicolumn{3}{|c|}{ Porosidade do solo } \\
\hline & & & & Macro & Micro & Total \\
\hline & $\mathrm{g} \mathrm{kg}^{-1}$ & $\mathrm{~mm}$ & $\mathrm{Mg} \mathrm{m}^{-3}$ & 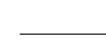 & $\mathrm{m}^{3} \mathrm{~m}^{-3}$ & \\
\hline & & Estádio & chimento dos legumes & ijão-miú & & \\
\hline $\mathrm{ESC}^{(3)}$, sem adubação & 31 & 3,85 & 1,33 & 0,16 & 0,29 & 0,45 \\
\hline ESC, adubação mineral & 26 & 4,05 & 1,23 & 0,16 & 0,32 & 0,48 \\
\hline ESC, adubação orgânica & 26 & 4,03 & 1,27 & 0,16 & 0,29 & 0,45 \\
\hline $\mathrm{SD}^{(4)}$, sem adubação & 32 & 4,75 & 1,46 & 0,09 & 0,34 & 0,43 \\
\hline SD, adubação mineral & 28 & 4,75 & 1,48 & 0,12 & 0,31 & 0,42 \\
\hline \multirow[t]{2}{*}{ SD, adubação orgânica } & 20 & 4,56 & 1,43 & 0,13 & 0,29 & 0,42 \\
\hline & \multicolumn{6}{|c|}{ Semeadura do sorgo } \\
\hline ESC, sem adubação & 32 & 4,20 & 1,14 & 0,22 & 0,28 & 0,50 \\
\hline ESC, adubação mineral & 30 & 3,80 & 1,18 & 0,23 & 0,25 & 0,48 \\
\hline ESC, adubação orgânica & 32 & 4,46 & 1,16 & 0,22 & 0,25 & 0,47 \\
\hline SD, sem adubação & 40 & 3,97 & 1,23 & 0,18 & 0,30 & 0,47 \\
\hline SD, adubação mineral & 30 & 3,97 & 1,28 & 0,15 & 0,32 & 0,47 \\
\hline \multirow[t]{2}{*}{ SD, adubação orgânica } & 30 & 4,07 & 1,42 & 0,12 & 0,28 & 0,41 \\
\hline & \multicolumn{6}{|c|}{ Estádio de maturação do sorgo } \\
\hline ESC, sem adubação & 27 & 3,87 & 1,33 & 0,15 & 0,33 & 0,48 \\
\hline ESC, adubação mineral & 33 & 3,66 & 1,40 & 0,11 & 0,31 & 0,43 \\
\hline ESC, adubação orgânica & 24 & 4,06 & 1,38 & 0,14 & 0,32 & 0,45 \\
\hline SD, sem adubação & 25 & 4,52 & 1,28 & 0,15 & 0,33 & 0,48 \\
\hline SD, adubação mineral & 22 & 4,62 & 1,38 & 0,14 & 0,29 & 0,43 \\
\hline SD, adubação orgânica & 23 & 4,86 & 1,48 & 0,11 & 0,31 & 0,41 \\
\hline
\end{tabular}

(1) Matéria orgânica. ${ }^{(2)}$ Diâmetro médio ponderado de agregados. ${ }^{(3)}$ Escarificação. ${ }^{(4)}$ Semeadura direta.

Quadro 3. Cobertura por resíduo cultural, rugosidade superficial induzida pelo preparo e consolidação da camada arável do solo, avaliadas por ocasião da realização do primeiro teste de erosão (semeadura das culturas, verões de 2007/2008 e 2008/2009), em cada ciclo cultural, nos tratamentos estudados

\begin{tabular}{|c|c|c|c|c|}
\hline \multirow{2}{*}{ Tratamento } & \multicolumn{2}{|c|}{ Cobertura por resíduo cultural ${ }^{(1)}$} & \multicolumn{2}{|c|}{ Semeadura do feijão- miúdo e do sorgo } \\
\hline & $\begin{array}{l}\text { Semeadura do } \\
\text { feijão-miúdo }^{(2)}\end{array}$ & $\underset{\text { sorgo }^{(3)}}{\text { Semeadura do }}$ & $\begin{array}{l}\text { Rugosidade induzida } \\
\text { pelo preparo }\end{array}$ & $\begin{array}{l}\text { Consolidação da } \\
\text { camada arável }\end{array}$ \\
\hline & \multicolumn{2}{|c|}{$\mathrm{m}^{2} \mathrm{~m}^{-2}$} & & \\
\hline $\mathrm{ESC}^{(4)}$, sem adubação & 0,19 & 0,35 & Média/grande & Ausente \\
\hline ESC, adubação mineral & 0,18 & 0,63 & Média/grande & Ausente \\
\hline ESC, adubação orgânica & 0,16 & 0,57 & Média/grande & Ausente \\
\hline $\mathrm{SD}^{(5)}$, sem adubação & 0,57 & 0,69 & Mínima/pequena & Presente \\
\hline $\mathrm{SD}$, adubação mineral & 0,52 & 1,00 & Mínima/pequena & Presente \\
\hline SD, adubação orgânica & 0,62 & 0,96 & Mínima/pequena & Presente \\
\hline
\end{tabular}

${ }^{(1)}$ A cobertura do solo no estádio fenológico de enchimento de legumes do feijão-miúdo e de maturação do sorgo era de $100 \%$ em todos os tratamentos, constituída por resíduos culturais remanescentes, alguma vegetação espontânea e as próprias plantasteste em crescimento. ${ }^{(2)}$ Resíduos culturais remanescentes predominantemente constituídos de vegetação espontânea dessecada. ${ }^{(3)}$ Resíduos culturais remanescentes de aveia-preta e de alguma vegetação espontânea dessecada. ${ }^{(4)}$ Escarificação. ${ }^{(5)}$ Semeadura direta.

mobilizado pelo escarificador. Assim, do mesmo modo como para a rugosidade superficial induzida pelo preparo, verificar-se-á que a consolidação da superfície do solo também influenciou os atributos de erosão hídrica avaliados neste estudo.
No quadro 4 são apresentados os resultados da avaliação dos atributos de planta medidos neste estudo, efetuada ao redor de 90 dias da semeadura das culturas, antecedendo o segundo teste de erosão realizado na pesquisa. Analisando os dados, verifica- 
Quadro 4. Atributos de planta medidos no estudo, avaliados ao redor de 90 dias da semeadura das culturas (estádio fenológico de enchimento de legumes, no caso do feijão-miúdo; e de maturação, no do sorgo), antecedendo o segundo teste de erosão realizado em cada uma delas, nos tratamentos estudados

\begin{tabular}{|c|c|c|c|c|c|c|}
\hline \multirow{2}{*}{ Tratamento } & \multicolumn{2}{|c|}{ Altura média de plantas } & \multicolumn{2}{|c|}{ Biomassa aérea } & \multicolumn{2}{|c|}{ Biomassa raizes $(0-0,10 \mathrm{~m})$} \\
\hline & Feijão-miúdo & Sorgo & Feijão-miúdo & Sorgo & Feijão-miúdo & Sorgo \\
\hline & $\longrightarrow \mathrm{m}$ & - & & 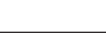 & $\mathrm{g} \mathrm{ha}^{-1}$ & - \\
\hline $\mathrm{ESC}^{(1)}$, sem adubação & n/avaliado & 1,62 & 3.700 & 10.800 & 4.520 & 1.050 \\
\hline ESC, adubação mineral & n/avaliado & 2,08 & 5.800 & 17.400 & 5.100 & 1.990 \\
\hline ESC, adubação orgânica & n/avaliado & 2,08 & 4.213 & 19.500 & 4.990 & 2.360 \\
\hline $\mathrm{SD}^{(2)}$, sem adubação & n/avaliado & 1,44 & 2.470 & 9.100 & 3.540 & 1.000 \\
\hline SD, adubação mineral & n/avaliado & 2,04 & 3.963 & 16.900 & 4.240 & 1.350 \\
\hline SD, adubação orgânica & n/avaliado & 2,04 & 4.088 & 16.900 & 3.470 & 1.740 \\
\hline
\end{tabular}

(1) Escarificação. ${ }^{(2)}$ Semeadura direta.

se que os atributos em consideração variaram tanto entre os métodos de preparo do solo quanto entre os tipos de adubação.

A altura média do sorgo, exceto a condição sem adubação, na qual foi maior na escarificação do que na semeadura direta e menor do que em qualquer uma das condições com adubação, praticamente não se diferenciou entre os métodos de preparo do solo e tipos de adubação. No que se refere à biomassa vegetal aérea (dossel), em ambas as culturas e em qualquer das condições de adubação, ela foi maior na escarificação do que na semeadura direta. Em relação ao tipo de adubação, na situação com semeadura direta a biomassa vegetal aérea não foi influenciada em nenhuma das culturas, enquanto na escarificação ela foi maior na adubação mineral em relação à primeira cultura referida e maior na adubação orgânica em relação à segunda cultura, com o sorgo tendo produzido mais biomassa aérea do que o feijão-miúdo. Quanto à biomassa de raízes, de modo parecido ao da biomassa vegetal aérea, em ambas as culturas e em qualquer das condições de adubação, foi maior na escarificação do que na semeadura direta e, em ambos os tipos de preparo, foi menor na condição sem adubação do que na com adubação. No tocante ao tipo de adubação em si, o comportamento da biomassa de raízes foi irregular no que se relaciona tanto com os métodos de preparo do solo quanto com os tipos de cultura. Também, observa-se no quadro 4 a pequena quantidade de raízes produzida pela cultura do sorgo na camada de solo de 0-0,10 m, comparada à do feijão-miúdo, contrariamente ao observado com a biomassa aérea, o que não era esperado.

A maior produção de biomassa vegetal aérea e subterrânea nos tratamentos com escarificação, em qualquer das condições de adubação e em ambas as culturas, se deveu à mobilização do solo, o que aumentou a relação área/volume de solo e, como consequência, diminuiu sua densidade global, ao mesmo tempo em que aumentou a macroporosidade e a porosidade total da camada de solo mobilizada, facilitando a penetração de raízes nesta e permitindo maior crescimento vegetal como um todo. Há ainda que se considerar que, em decorrência das melhores condições físicas superficiais e subsuperficiais do solo na escarificação, comparadas às da semeadura direta, aumentam muito também as taxas de infiltração de água no solo, o que eleva o seu conteúdo de umidade para posterior aproveitamento pelas plantas, além de disponibilizar melhor os nutrientes, em função do aumento da sua dissolução em água. A menor produção de biomassa vegetal (aérea e subterrânea) nos tratamentos sem adubação, em ambas as culturas e nos dois métodos de preparo do solo, foi causada pela menor disponibilidade de elementos nutritivos necessários ao crescimento vegetal. Quanto ao fato de as diferenças nos atributos de planta, causadas pelo tipo de adubação (mineral e orgânica), não terem sido regulares, nem em relação às culturas nem em relação aos métodos de preparo do solo, o assunto fica para ser investigado melhor em estudos futuros. Possíveis causas para isso, entretanto, foram: pouco tempo de experimentação (três anos), falta de repetições nos tratamentos e pequeno número de amostras coletadas nas parcelas experimentais, para devidamente avaliar esses atributos de planta, mas principalmente no que se refere à biomassa de raízes, que foi a que apresentou maior irregularidade nos resultados. O esperado era obter maior quantidade de biomassa vegetal na adubação mineral, o que, em um e outro caso, ocorreu, em razão da maior disponibilidade de nutrientes nesta, devido à sua maior solubilidade em água, comparada à adubação orgânica.

No quadro 5 são apresentados os valores do teor de água no solo, em duas de suas camadas, avaliados em épocas distintas durante a condução dos experimentos, antecedendo os testes de erosão nelas realizados. Essa variável perfaz outra condição da camada superior do solo que pode alterar muito as variáveis de erosão hídrica. Verifica-se no referido quadro que os valores de teor de água no solo, para uma mesma camada de solo avaliada e para uma mesma época de avaliação, variaram relativamente pouco entre os tratamentos, porém apresentaram alguma variação entre as épocas 
Quadro 5. Teor de água no solo, em duas de suas camadas, avaliado em épocas distintas durante a condução dos experimentos (duas no verão de 2007/2008 e duas no verão de 2008/2009), antecedendo os testes de erosão

\begin{tabular}{|c|c|c|c|c|c|c|c|c|}
\hline \multirow{3}{*}{ Tratamento } & \multicolumn{8}{|c|}{ Teor de água no solo } \\
\hline & \multicolumn{2}{|c|}{$\begin{array}{l}\text { Semeadura do } \\
\text { feijão-miúdo }\end{array}$} & \multicolumn{2}{|c|}{$\begin{array}{l}\text { Enchimento de legumes } \\
\text { feijão-miúdo }\end{array}$} & \multicolumn{2}{|c|}{$\begin{array}{l}\text { Semeadura } \\
\text { do sorgo }\end{array}$} & \multicolumn{2}{|c|}{$\begin{array}{l}\text { Maturação } \\
\text { do sorgo }\end{array}$} \\
\hline & $0-0,1 \mathrm{~m}$ & $0,1-0,2 \mathrm{~m}$ & $0-0,1 \mathrm{~m}$ & $0,1-0,2 \mathrm{~m}$ & $0-0,1 \mathrm{~m}$ & $0,1-0,2 \mathrm{~m}$ & $0-0,1 \mathrm{~m}$ & $0,1-0,2 \mathrm{~m}$ \\
\hline & & & & $-\mathrm{kg} \mathrm{k}$ & & & & \\
\hline $\mathrm{ESC}^{(1)}$, sem adubação & 0,16 & 0,17 & 0,10 & 0,11 & 0,16 & 0,17 & 0,16 & 0,17 \\
\hline ESC, adubação mineral & 0,13 & 0,14 & 0,09 & 0,09 & 0,19 & 0,17 & 0,11 & 0,14 \\
\hline ESC, adubação orgânica & 0,13 & 0,15 & 0,09 & 0,09 & 0,12 & 0,17 & 0,14 & 0,15 \\
\hline $\mathrm{SD}^{(2)}$, sem adubação & 0,16 & 0,16 & 0,14 & 0,12 & 0,17 & 0,17 & 0,15 & 0,15 \\
\hline SD, adubação mineral & 0,13 & 0,13 & 0,09 & 0,10 & 0,16 & 0,15 & 0,13 & 0,13 \\
\hline SD, adubação orgânica & 0,12 & 0,13 & 0,09 & 0,11 & 0,14 & 0,16 & 0,13 & 0,13 \\
\hline
\end{tabular}

(1) Escarificação. ${ }^{(2)}$ Semeadura direta.

de avaliação, com os maiores deles estando sempre associados à camada de solo de 0,10-0,20 m. Com base nisso, pode-se assumir que a umidade antecedente do solo, para um mesmo teste de erosão ou uma mesma época de avaliação, não constituiu causa de variação nos resultados da pesquisa, no que se refere aos atributos de erosão hídrica nela avaliados.

\section{Variáveis de erosão hídrica}

Na figura 1 são apresentados os resultados da avaliação do tempo de início da enxurrada (Ti), nos testes de erosão realizados na pesquisa. Verifica-se que, exceto um caso isolado (SD, s/ad.), cujo valor foi relativamente pequeno (pouco maior do que $15 \mathrm{~min}$ ), no teste de erosão realizado logo após a semeadura das culturas (Figura 1a) os valores de Ti foram relativamente grandes (próximos de 30 a quase 60 min), em todos os tratamentos e nas duas culturas, porém maiores na escarificação do que na semeadura direta, e maiores ainda nas condições com adubação do que na sem adubação, com diferenças relativamente pequenas e irregulares entre as culturas e os tipos de adubação. Já no teste realizado no estádio fenológico de enchimento de legumes do feijão-miúdo e no de maturação do sorgo (Figura $1 \mathrm{~b}$ ), os valores de $\mathrm{Ti}$, de modo geral, foram menores do que os observados no primeiro teste, com valores máximos pouco maiores do que $30 \mathrm{~min}$, mas dessa vez com diferença marcante entre os tipos de cultura (valores muito menores no feijão-miúdo do que no sorgo, exceto o tratamento SD, ad. min., em que foram parecidos nas duas culturas), e com comportamento parecido ao do primeiro teste quanto aos métodos de preparo de solo e tipos de adubação.

Os maiores valores de tempo de início da enxurrada na escarificação no teste de erosão realizado logo após a semeadura das culturas, comparados aos da semeadura direta, podem ser explicados, principalmente, pela maior rugosidade superficial do



Figura 1. Tempo de início da enxurrada (Ti) nos testes de erosão realizados logo após a semeadura das culturas (a) e no estádio fenológico de enchimento de legumes do feijãomiúdo e no de maturação do sorgo (b), nos tratamentos estudados.

solo na mesma (Quadro 3) e, decorrente dela, também maior porosidade total na camada mobilizada, o que favoreceu a infiltração e a retenção superficial da água da chuva. Deve-se associar a isso, entretanto, a pequena extensão de superfície de solo consolidada na escarificação, comparada à da semeadura direta, o que também favoreceu a infiltração e a retenção superficial da água da chuva, apesar de a cobertura do solo por resíduo cultural ter sido bem menor na escarificação (média de $18 \%$ para o feijão-miúdo e de $52 \%$ para o sorgo) do que na semeadura direta (média de $57 \%$ para o feijão-miúdo e de $88 \%$ para o sorgo). Os 
menores valores de tempo de início da enxurrada no teste de erosão realizado no estádio de enchimento de legumes do feijão-miúdo e no de maturação do sorgo, comparados ao realizado logo após a semeadura dessas culturas, especialmente os do feijão-miúdo, provavelmente se deveram às inferiores condições físicas de superfície e subsuperfície do solo nesses segundos testes para infiltrar e reter água da chuva, especialmente a rugosidade superficial induzida pelo preparo e decorrente porosidade total da camada mobilizada, cujas capacidades para esses processos de captação de água decaem com o passar do tempo, perdendo efeito nas suas funções de retardamento da enxurrada, conforme também observado por Cogo (1981), Cogo et al. (1983) e Norton et al. (1985). As diferenças relativamente pequenas e irregulares no tempo de início da enxurrada entre os tipos de adubação podem ser consideradas normais, tendo em vista o pouco tempo de experimentação para que esses materiais causassem efeito nas condições físicas internas do solo. Os menores valores de tempo de início da enxurrada na cultura do feijão-miúdo, no segundo teste de erosão, comparados aos do sorgo, exceto um caso isolado, em que foram semelhantes, provavelmente se deveram ao menor teor de água no solo antecedente às chuvas simuladas, na referida cultura (Quadro 3).

Na figura 2 são apresentados os resultados da avaliação da altura da lâmina de água da chuva infiltrada e retida na superfície do solo no período de pré-enxurrada (LAPE). Essa variável tem paralelismo total com o tempo de início da enxurrada, uma vez que é diretamente proporcional a ele. Assim, toda a

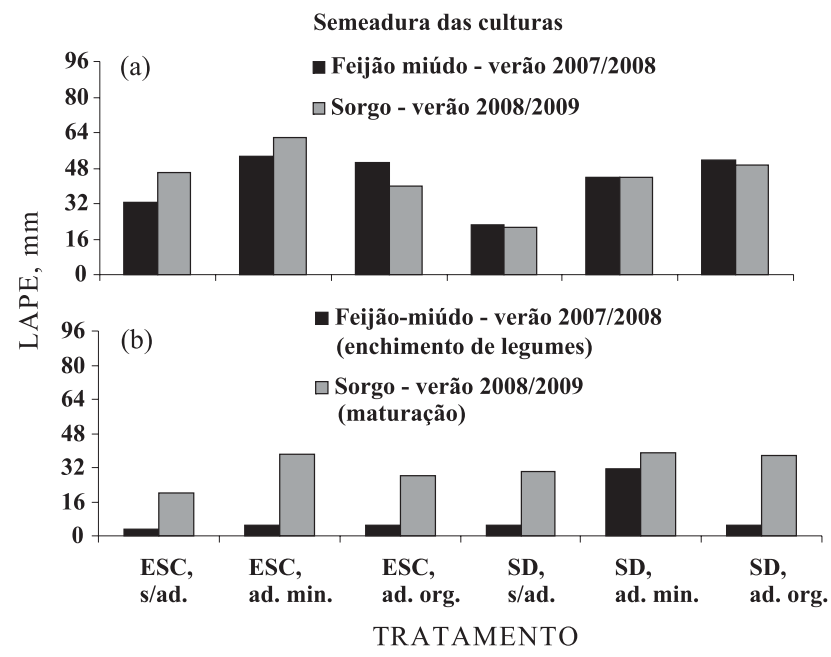

Figura 2. Altura da lâmina de água da chuva infiltrada e retida na superfície do solo no período de pré-enxurrada (LAPE), nos testes de erosão realizados logo após a semeadura das culturas (a) e no estádio fenológico de enchimento de legumes do feijão-miúdo e no de maturação do sorgo (b), nos tratamentos estudados. argumentação usada na discussão do tempo de início da enxurrada é válida também na discussão da LAPE, exceto um aspecto, muito importante, do ponto de vista de aplicação prática dos resultados. Trata-se da quantidade de água da chuva aportada e efetivamente retida no solo, para posterior aproveitamento pelas plantas. Assim, analisando os dados da figura 2, observa-se que, em qualquer dos tratamentos estudados, somente a situação com a cultura do feijãomiúdo, no segundo teste de erosão, apresentou altura de lâmina de água da chuva retida no sistema, anterior à enxurrada, pequena (menor do que $5 \mathrm{~mm}$ ), exceto um caso discrepante (SD, ad. $\mathrm{min}$ ), em que foi relativamente grande (quase $30 \mathrm{~mm}$ ). Para os demais casos, pode-se considerar que os valores da variável em consideração foram grandes e muito grandes (desde próximos de 20 até quase $60 \mathrm{~mm}$, respectivamente), o que, em princípio, garantiria boa quantidade de água no solo para revigoramento das plantas, em situação de déficit hídrico.

$\mathrm{Na}$ figura 3 são apresentados os resultados da avaliação da perda total de água da chuva na forma de enxurrada (PTA) nos testes de erosão realizados na pesquisa (Figura 3a, logo após semeadura; e Figura 3b, estádios de enchimento de legumes e maturação das culturas), nos tratamentos estudados. Verifica-se que, exceto três casos, com valores entre 30 e $40 \%$, a PTA foi relativamente pequena em todas as situações da pesquisa, ou seja, menos de $20 \%$ da quantidade total de chuva aplicada. Já nos testes realizados logo após a semeadura das culturas (Figura 3a), os valores de PTA foram menores nos tratamentos com escarificação do que nos com semeadura direta, bem como menores nas condições com adubação do que na sem adubação, em ambas as culturas, mas menores na do sorgo do que na do feijãomiúdo e, praticamente, sem diferença entre os tipos de adubação na semeadura direta e com valores maiores na adubação orgânica na escarificação, em qualquer dos tipos de cultura. Já nos testes realizados no estádio de enchimento de legumes do feijão-miúdo e no de maturação do sorgo (Figura 3b), verifica-se que o comportamento da perda total de água foi parecido ao observado nos testes de erosão realizados logo após a semeadura das culturas, exceto pelo fato de que, de modo contrário ao observado na primeira época, os valores de PTA foram expressivamente maiores na cultura do sorgo do que na do feijão-miúdo. Fundamentalmente, esses resultados estiveram associados à maior rugosidade e à menor consolidação superficial do solo na escarificação, resultando em maiores capacidades de infiltração e retenção superficiais da água da chuva, comparada à semeadura direta, bem como devido à melhoria das condições físicas do solo na sua camada superficial com o passar do tempo (maior quantidade de biomassa vegetal aérea e subterrânea aportada pelas culturas, conferindo maior proteção e maior resistência ao solo contra a ação erosiva). Quanto à adubação, verificase que ela teve efeito positivo na redução da perda de 


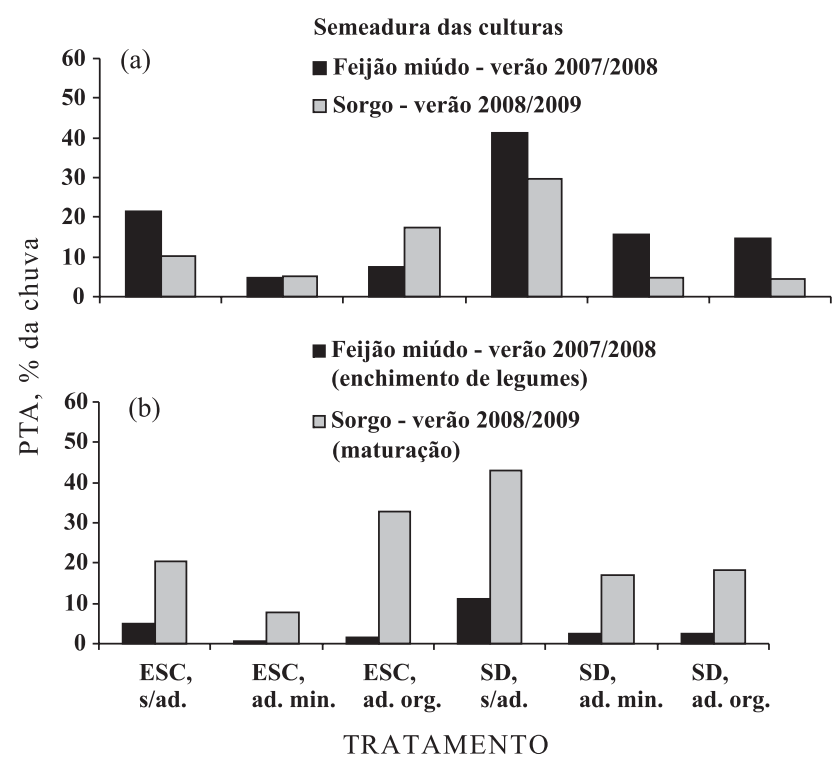

Figura 3. Perda total de água (PTA) nos testes de erosão realizados logo após a semeadura das culturas (a) e no estádio fenológico de enchimento de legumes do feijão-miúdo e no de maturação do sorgo (b), nos tratamentos estudados.

água da chuva na forma de enxurrada (Figura 1a,b), comparada à sua ausência, porém sem tendência definida quanto à influência de seu tipo (mineral e orgânica), o que, em parte, pode ser explicado pelo pouco tempo de experimentação e pelas variações ao acaso.

$\mathrm{Na}$ figura 4 são apresentados os resultados da avaliação da perda total de solo (PTS), essencialmente nos testes de erosão realizados logo após a semeadura das culturas (não houve perda de solo por erosão nos testes realizados no estádio fenológico de enchimento de legumes do feijão-miúdo e no de maturação do sorgo, em razão da completa cobertura do solo), nos dois anos de experimentação. Analisando os dados no referido quadro, verifica-se que, de modo contrário ao observado em relação à PTA, a PTS foi menor nos tratamentos com semeadura direta do que nos com escarificação, em ambas as culturas e em qualquer das condições de adubação, bem como menor nas condições com adubação do que na sem adubação, em qualquer dos métodos de preparo do solo, sem tendência definida quanto à influência de seu tipo (mineral e orgânica). Observa-se também na figura 4 que a perda total de solo foi maior quando se efetuou a semeadura do feijão-miúdo do que a do sorgo, em qualquer das situações criadas na pesquisa.

Os menores valores de PTS na semeadura direta, comparados aos da escarificação, deveram-se à sua maior cobertura por resíduos culturais e maior consolidação superficial (Quadro 3) e, por conseguinte, maior resistência à ação erosiva, independentemente das culturas e das condições de adubação. Os maiores valores de PTS na ausência de adubação, em qualquer das culturas e métodos de preparo de solo, deveramse ao menor crescimento vegetal sob esta, o que, consequentemente, produziu menor quantidade de biomassa vegetal e propiciou menor percentagem de cobertura ao solo, comparada às condições com adubação (Quadros 4 e 3). A menor perda total de solo logo após a semeadura do sorgo, comparada à do feijão-miúdo, em qualquer das situações da pesquisa, deveu-se ao fato de os valores de cobertura do solo por resíduos culturais terem sido maiores (69 a 100 \% para o sorgo e 52 a 62 \% para o feijão-miúdo - Quadro 3). O comportamento irregular dos valores de PTS em relação ao tipo de adubação, em qualquer das situações da pesquisa, provavelmente em parte esteve associado ao pouco tempo de experimentação e às variações ao acaso nas condições internas do solo, conforme comentado em relação à perda total de água.

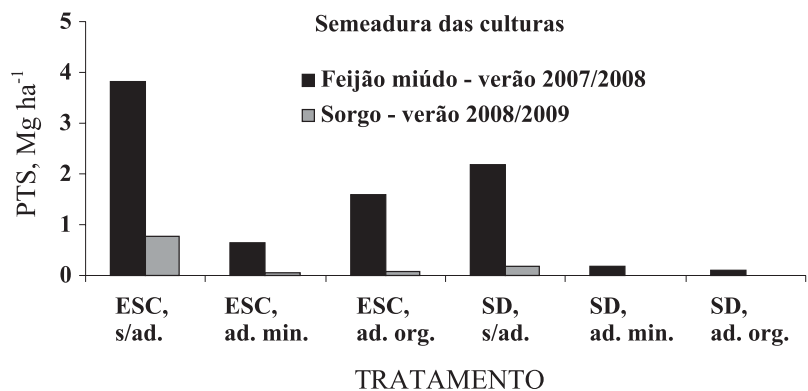

Figura 4. Perda total de solo (PTS) nos testes de erosão realizados logo após a semeadura das culturas, nos tratamentos estudados (Obs.: não houve perda mensurável de solo nos testes de erosão realizados no estádio fenológico de enchimento de legumes do feijão-miúdo e no de maturação do sorgo).

\section{CONCLUSÕES}

1. A mudança no tipo de uso da terra (pastagem nativa para culturas anuais em fileira), excluindo a condição sem adubação, em geral não causou perdas relevantes de solo e água por erosão hídrica, o que fortalece a recomendação de preparos conservacionistas de solo para se fazer agricultura com plantas cultivadas, especialmente as de ciclo anual e dispostas em fileira.

2. A mobilização do solo pela escarificação, na maior parte dos casos, favoreceu a infiltração e a retenção superficial da água da chuva e, em decorrência, diminuiu a enxurrada, ao mesmo tempo em que controlou satisfatoriamente a erosão.

3. A ausência de mobilização do solo na semeadura direta, também na maior parte dos casos, induziu a formação de maior enxurrada, porém controlou melhor a perda de solo por erosão. 
4. Comparadas à condição sem adubação, a adubação mineral e a adubação orgânica contribuíram para reduzir a enxurrada e a erosão nos dois métodos de preparo do solo investigados, sem diferenças definidas entre elas em qualquer um destes últimos.

\section{LITERATURA CITADA}

BERTOL, I.; ALBUQUERQUE, J.A.; LEITE, D.; AMARAL, A.J. \& ZOLDAN JUNIOR, W.A. Propriedades físicas do solo sob preparo convencional e semeadura direta em rotação e sucessão de culturas, comparadas às do campo nativo. R. Bras. Ci. Solo, 28:155-163, 2004.

CASTRO, L.G.; COGO, N.P. \& VOLK, L.B.S. Alterações na rugosidade superficial do solo pelo preparo e pela chuva em solo com cessamento de cultivo, na ausência e na presença de cobertura por resíduo cultural, e sua relação com a erosão hídrica. R. Bras. Ci. Solo, 30:339-352, 2006.

COGO, N.P. Effect of residue cover, tillage-induced roughness and slope length on erosion and related parameters. West Lafayette, Purdue University, 1981. 346p. (Tese de Doutorado).

COGO, N.P.; MOLDENHAUER, W.C. \& FOSTER, G.R. Effect of residue cover, tillage-induced roughness, and runoff velocity on size distribution of eroded soil aggregates. Soil Sci. Soc. Am. J., 47:1005-1008, 1983.

COGO, N.P.; MOLDENHAUER, W.C. \& FOSTER, G.R. Soil loss reductions from conservation tillage practices. Soil Sci. Soc. Am. J., 48:368-373, 1984.

COGO, N.P.; LEVIEN, R. \& SCHWARZ, R.A. Perdas de solo e água por erosão hídrica influenciadas por métodos de preparo, classes de declive e níveis de fertilidade do solo. R. Bras. Ci. Solo, 27:743-753, 2003.

COMISSAO DE QUÍMICA E FERTILIDADE DO SOLO CQFSRS/SC. Manual de adubação e calagem dos estados do RS e SC. 10.ed. Porto Alegre, Sociedade Brasileira de Ciência do Solo/Núcleo Regional Sul, 2004. 394p.

DEBIASI, H. Recuperação física de um Argissolo compactado e suas implicações sobre o sistema solo-máquina-planta. Porto Alegre, Universidade Federal do Rio Grande Sul, 2008. 263p (Tese de Doutorado)

DIANA, G.; BENI, C. \& MARCONI, S. Organic and mineral fertilization: Effects on physical characteristics and boron dynamic in an agricultural soil. Comm. Soil Sci. Plant Anal., 39:1332-1351, 2008.

EMPRESA BRASILEIRA DE PESQUISA AGROPECUÁRIA - EMBRAPA. Manual de métodos de análises de solo. 2.ed. Rio de Janeiro, Ministério da Agricultura e do Abastecimento, 1997. 212p.

FORSYTHE, W. Fisica de suelos: Manual de laboratorio. San José, Costa Rica, IICA, 1975. 212p.

GILlES, L.; COGO, N.P.; BISSANI, C.A.; BAGATINI, T. \& PORTELA, J.C. Perdas de água, solo, matéria orgânica e nutriente por erosão hídrica na cultura do milho implantada em área de campo nativo, influenciadas por métodos de preparo do solo e tipos de adubação. R. Bras. Ci. Solo, 33:1427-1440, 2009.
HARTWIG, R.O. \& LAFLEN, J.M. A meterstick method for measuring crop residue cover. J. Soil Water Conserv., 33:90-91, 1978.

HUDSON, N.W. Soil conservation. 3.ed. Ames, lowa State University Press, 1995. 391p.

KEMPER, W.D. \& CHEPIL, W.S. Size distribution of aggregates. In: BLACK, C.A., ed. Methods of soil analysis, physical and mineralogical properties, including statistics, measurement and sampling. Madison, Am. Soc. Agric., 499-510, 1965.

NORTON, L.D.; COGO, N.P. \& MOLDENHAUER, W.C. Effectiveness of mulch in controlling soil erosion. In: EL SWAIFY, S.A.; MOLDENHAUER, W.C. \& LO, A., eds. Soil erosion and conservation. Ankeny, Soil Conservation Society of America, 1985. p.237-247.

OLIVEIRA, G.C.; DIAS JUNIOR, M.S.; RESK, D.V.S. \& CURI, N. Compressibilidade de um Latossolo Vermelho argiloso de acordo com a tensão de água no solo, uso e manejo. R. Bras. Ci. Solo, 27:773-781, 2003.

PIRES, A.A.; MONNERAT, P.H.; MARCIANO, C.R.; PINHO, L.G.R.; ZAMPIROLLI, P.D.; ROSA, R.C.C. \& MUNIZ, R.A.0. Efeito da adubação alternativa do maracujazeiroamarelo nas características químicas e físicas do solo. R. Bras. Ci. Solo, 32:1997-2005, 2008.

PORTELA, J.C.; COGO, N.P.; BAGATINI, T.; CHAGAS, J.P. \& PORTZ, G. Restauração da estrutura do solo por seqüências culturais implantadas em semeadura direta, e sua relação com a erosão hídrica em distintas condições físicas de superfície. R. Bras. Ci. Solo, 34:1353-1364, 2010.

RENARD, K.G.; FOSTER, G.R.; WEESIES, G.A.; McCOOL, D.K. \& YODER, D.C. Predicting soil erosion by water: a guide to conservation planning with the revised universal soil loss equation (RUSLE). Washington, USDA, 1997. 384p. (Agriculture Handbook, 703).

SCHRÖDER, P. et al. Land use and sustainability: FAM research network on agroecosystems. Geoderma, Amsterdan, 105:155-166, 2002.

STRECK, E.V. \& COGO, N.P. Reconsolidation of the soil surface after tillage discontinuity, with and without cultivation, related to erosion and its prediction with RUSLE. R. Bras. Ci. Solo, 27:141-152, 2003.

STRECK, E.V.; KÄMPF, N.; DALMOLIN, R.S.D.; KLAMT, E.; NASCIMENTO, P.C. \& SCHNEIDER, P. Solos do Rio Grande do Sul. 2.ed. Porto Alegre, Emater/RS/UFRGS, 2008. 222p.

SWANSON, N.P. A rotating-boom rainfall simulador. Trans. ASAE, 26:1738-1743, 1965.

VOLK, L.B.S; COGO, N.P. \& STRECK, E.V. Erosão hídrica influenciada por condições físicas de superfície e subsuperfície do solo resultantes do seu manejo, na ausência de cobertura vegetal. R. Bras. Ci. Solo, 28:763774, 2004.

VOLK, L.B.S. \& COGO, N.P. Inter-relação biomassa vegetal subterrânea-estabilidade de agregados-erosão hídrica em solo submetido a diferentes formas de manejo. R. Bras. Ci. Solo, 32:1713-1722, 2008. 
VOLK, L.B.S. \& COGO, N.P. Relações entre tamanho de sedimentos erodidos, velocidade da enxurrada, rugosidade superficial criada pelo preparo e tamanho de agregados em solo submetido a diferentes manejos. R. Bras. Ci. Solo, $33: 1459-1471,2009$

WISCHMEIER, W.H. Conservation tillage to control water erosion. In: NATIONAL CONSERVATION TILLAGE CONFERENCE, Ankeny, 1973. Proceedings.... Ankeny, Soil Conservation Society of America, 1973. p.133-141.
WISCHMEIER, W.H. \& SMITH, D.D. Predicting rainfall erosion losses; a guide to conservation planning. Washington, USDA, 1978. 58p. (Agricultural Handbook, 537).

ZHAO, Y.; WANG, P.; LI, J.; CHEN, Y.; YING, X. \& LIU, S. The effects of two organic manures on soil properties and crop yields on a temperate calcareous soil under a wheat maize cropping system, Eur. J. Agron, 31:36-42, 2009 . 